\title{
Annual incidence rates of herpes zoster among an immunocompetent population in the United States
}

Barbara H. Johnson ${ }^{1 * \dagger}$, Liisa Palmer ${ }^{1}$, Justin Gatwood ${ }^{1 \dagger}$, Gregory Lenhart ${ }^{1}$, Kosuke Kawai ${ }^{2}$ and Camilo J. Acosta ${ }^{2}$

\begin{abstract}
Background: Herpes zoster ( $\mathrm{HZ}$ ), also known as shingles, is a painful and commonly occurring condition in the United States. In spite of a universally recommended vaccine for use in immunocompetent adults aged 60 years and older, $\mathrm{HZ}$ continues to impact the American public, and a better understanding of its current incidence is needed. The objective of the current study is to estimate the overall and age- and gender-specific incidence rates (IRs) of HZ among an immunocompetent US population in 2011 following availability of a vaccine.
\end{abstract}

Methods: Claims data from the Truven Health MarketScan ${ }^{\oplus}$ Research databases between 01/01/2011 and 12/31/2011 were extracted. Immunocompetent adult patients, enrolled as of January 1, 2011 were analyzed. The denominator was defined as eligible subjects who were immunocompetent, had no evidence of zoster vaccination, and no diagnosis of HZ (International Classification of Diseases, Ninth Revision, Clinical Modification diagnosis code 053.xx) in the 90 days prior to January 1, 2011. Subjects contributed person-days to the denominator until the occurrence of one of the following events: end of continuous enrollment in the database, a claim for zoster vaccination, diagnosis of $\mathrm{HZ}$ or end of the observation period (December 31, 2011). The numerator was defined as enrollees within the denominator file exhibiting evidence of $\mathrm{HZ}$. Annual IRs were calculated for the entire population in the database as well as by gender and age group; standardized IRs were also produced using the 2010 US Census data.

Results: The overall annual IR of HZ across all ages was 4.47 per 1000 person-years (95\% confidence interval [Cl]: 4.44-4.50) which monotonically increased with age from 0.86 (95 \% Cl: $0.84-0.88$ ) for those aged $\leq 19$ to 12.78 (95 \% Cl: 12.49-13.07) for patients $\geq 80$ years. The IR was 8.46 (95 \% Cl: 8.39-8.52) among adults $\geq 50$ years and 10.46 (95\% Cl: 10.35-10.56) among those aged $\geq 60$ years. Women compared to men had higher $\mathrm{HZ}$ incidence (5.25, $95 \%$ Cl: 5.21-5.29 vs. 3.66, $95 \%$ Cl: 3.62-3.69) and this was seen across all age groups. When adjusted for age and gender using 2010 US Census data, the annual IR was 4.63 per 1000 person-years (95 \% Cl: 4.61-4.66).

Conclusions: Despite the availability of a vaccine, $\mathrm{HZ}$ remains common among immunocompetent adults in the US with incidence rates of $\mathrm{HZ}$ observed to increase with age and be higher in women than men.

Keywords: Herpes zoster, Incidence rates, Immunocompetent, Vaccine

\footnotetext{
* Correspondence: barbara.h.johnson@truvenhealth.com

${ }^{\dagger}$ Equal contributors

'Outcomes Research, Truven Health Analytics, Ann Arbor, MI, USA

Full list of author information is available at the end of the article
} 


\section{Background}

Herpes zoster (HZ), or shingles, is caused by reactivation of the varicella zoster virus (VZV) and mainly affects the elderly population [1-3]. In the United States, over $99 \%$ of adults have serological evidence of VZV infection and are susceptible to $\mathrm{HZ}$ [4], and the individual lifetime risk of $\mathrm{HZ}$ is approximately $30 \%$ [5]. It is estimated that approximately 1 million new cases of $\mathrm{HZ}$ are diagnosed each year. While susceptibility to HZ increases with advancing age, the rate of incidence significantly increases among patients aged $>50$ years, with a drastic rise in the rate thereafter $[2,6]$. The incidence rate of $\mathrm{HZ}$ ranged between three and five per 1,000 person-years from prior studies in the US and other countries, depending on the population studied and immunocompetency of subjects $[5,7-10]$. However, estimates are prior to the introduction of a zoster vaccine in the United States.

Zostavax, a live attenuated zoster vaccine approved in the US for the prevention of $\mathrm{HZ}$ in immunocompetent adults 50 years of age and older, is recommended by the US Centers for Disease Control and Prevention's Advisory Committee on Immunization Practices (ACIP) for use among immunocompetent adults aged 60 years and older [11]. In a large randomized clinical trial, zoster vaccine was shown to reduce the incidence of $\mathrm{HZ}$ by $51.3 \%$ and the incidence of postherpetic neuralgia (PHN) by $66.5 \%$, in immunocompetent adults 60 years of age and older [6]. In addition, the Zostavax Efficacy and Safety Trial (ZEST) demonstrated that zoster vaccine reduced the risk of $\mathrm{HZ}$ in adults 50 to 59 [12]. The economic value of the zoster vaccine has been reviewed and synthesized elsewhere [13].

In spite of vaccine availability, $\mathrm{HZ}$ continues to pose a significant burden in the US. Despite ACIP recommendations, in 2011 only $15.8 \%$ of adults aged $\geq 60$ years reported ever receiving the zoster vaccine [14]. Previous studies found that the incidence rate of HZ has changed over time, and updated data on age-specific and sexspecific incidence rates using a nationwide database is important to understand the population at risk of $\mathrm{HZ}$. The objective of the current study is to estimate the overall and age- and sex-specific incidence rates of HZ among immunocompetent US adults in 2011 following availability of a vaccine.

\section{Methods}

Data source

This retrospective, observational cohort study was conducted using administrative claims data from two Truven Health MarketScan Research Databases - the Commercial Claims and Encounters and the Medicare Supplemental and Coordination of Benefits-for the period January 1, 2011 through December 31, 2011. Both databases include complete longitudinal records of inpatient services, outpatient services, long-term care, and prescription drug claims covered under a variety of fee-for-service and managed care health plans, including exclusive provider organizations, preferred provider organizations, point of service plans, indemnity plans, and health maintenance organizations. The MarketScan Research database records are de-identified and compliant with US patient confidentiality requirements, including the Health Insurance Portability and Accountability Act 1996. Permissions were not needed to utilize these data. Since this study used only de-identified patient records and did not involve the collection, use, or transmittal of individually identifiable data, Institutional Review Board approval was not necessary.

\section{Patient selection}

Patients with and without HZ (International Classification of Diseases, Ninth Revision, Clinical Modification [ICD-9$\mathrm{CM}$ ] diagnosis code 053.xx), enrolled as of January 1, 2011, having no claims for $\mathrm{HZ}$ or evidence of receiving shingles vaccination in the 90 days prior to January 1 , 2011, and meeting criteria for immunocompetent status were included. A series of selected ICD-9-CM diagnoses, procedures and treatment criteria, informed by the Centers for Disease Control and Prevention [11] were used to determine the immunocompetent status of each patient. Patients were excluded if they had ICD-9-CM diagnosis or procedure codes for hematologic malignancy, solid tumor malignancy, human immunodeficiency virus, chronic renal failure, nephrotic syndrome, and other select immunocompromising conditions. Patients were also excluded if they had evidence of organ transplantation, procedures indicating injection or infusion of cancer chemotherapeutic substance, immunotherapy as antineoplastic agent, poisoning by antineoplastic and immunosuppressive drugs, or treatment with chemotherapy, radiation therapy, corticosteroids, tumor necrosis factor inhibitors, protease inhibitors, reverse transcriptase inhibitors, azathioprine, cyclosporine, or tacrolimus.

\section{Annual incidence rate}

The annual incidence rates of $\mathrm{HZ}$ were calculated for the entire population observed in the database as well as by gender and age group $(<19,20-29,30-39,40-49$, $50-59,60-69,70-79,80+)$. Standardized incidence rates were also produced using the 2010 US Census data to produce overall and gender-specific rates by age group [15]. In addition, rates were reported for those aged $\geq 50$ and $\geq 60$ years.

\section{Statistical analysis}

Descriptive analyses were conducted to determine the demographic characteristics of the study cohort. Annual incidence rates of $\mathrm{HZ}$ in the immunocompetent were 
estimated by dividing the total unique number of incident $\mathrm{HZ}$ patients observed in the reporting year by the total number of person-years in the reporting year. The calculations for the denominator and numerator were performed as described previously [16]. The denominator was defined as eligible subjects who were immunocompetent, had no evidence of shingles vaccination, and no diagnosis of $\mathrm{HZ}$ in the 90 days prior to January 1, 2011. Subjects contributed person-days to the denominator until the occurrence of one of the following events: end of continuous enrollment in the database, a claim for zoster vaccine, diagnosis of $\mathrm{HZ}$, or end of the observation period (December 31, 2011). Rates of $\mathrm{HZ}$ were presented per 1,000 person-years, and the direct standardized rate and $95 \%$ confidence intervals were calculated by Chiang's normal approximation to Poisson rate sums [17]. A $p$-value of $<0.05$ was considered statistically significant.

\section{Results}

A total of 113,861 incident cases of $\mathrm{HZ}$ were observed in the database during the study period. Demographic characteristics of the study cohort are shown in Table 1. The mean population age was 52 (standard deviation: 17.8 ) years, with the majority aged $\geq 50$ years $(60 \%)$, and females comprising $60 \%$ of the study population. Over a third of patients resided in the south region of the United States (36\%) and the majority was covered by commercial insurance (79.1\%) (Table 1).

The overall annual incidence rate of HZ, across all ages of the study population, was 4.47 per 1,000 person-years (95\% confidence interval [CI]: 4.44-4.50) with higher rates observed among women than men $(5.25,95 \% \mathrm{CI}$ : 5.21-5.29 vs. 3.66, 95 \% CI: 3.62-3.69), respectively) across all age groups. The rate of $\mathrm{HZ}$ increased monotonically with age, ranging from 0.86 (95\% CI: 0.84-0.88) for those aged $\leq 19$ to 12.78 (95\% CI: 12.49-13.07) for immunocompetent $\mathrm{HZ}$ patients aged 80 and older (see Additional file 1). When the raw annual incidence rates of $\mathrm{HZ}$ across all ages were adjusted for age and sex using 2010 US Census data, the overall rate was 4.63 per 1,000 person-years (95 \% CI: 4.61, 4.66), with higher rates observed among women than men (5.52, 95 \% CI: 5.45-5.53 vs. 3.66, $95 \%$ CI: 3.62-3.79, respectively).

When incidence rates of $\mathrm{HZ}$ were examined for combined cohorts across age groups (i.e. those aged 50 and older and those 60 and older), the incidence rate increased from 8.46 (95 \% CI: 8.39-8.52) among adults 50 years and older to 10.46 (95 \% CI: 10.35-10.56) among those aged 60 years and older. Similarly, rates for males and females followed a nearly identical trend, increasing from 6.71 (95 \% CI: 6.63-6.80) to 8.73 (95\% CI: 8.60-8.87) in males and from 10.06 (95 \% CI: 9.9610.15 ) to 12.00 (95\% CI: $11.85-12.16$ ) in females (see Additional file 1).
Table 1 Demographic Characteristics of Incident Herpes Zoster Population

\begin{tabular}{|c|c|c|}
\hline & All HZ Patients & Total Denominator \\
\hline Demographic Characteristics & $N=113,861$ & $N=27,616,373$ \\
\hline Mean age, year (SD) & $52.0(17.8)$ & $36.9(21.0)$ \\
\hline \multicolumn{3}{|l|}{ Age Group, $n(\%)$} \\
\hline$<50$ & $45,588(40)$ & $18,972,479(69)$ \\
\hline $50-59$ & $29,266(26)$ & $4,620,496(17)$ \\
\hline $60-64$ & $14,959(13)$ & $1,866,686(7)$ \\
\hline $65-69$ & $6,636(6)$ & $674,081(2)$ \\
\hline $70-79$ & $10,231(9)$ & $884,385(3)$ \\
\hline $80+$ & $7,181,(6)$ & $598,246(2)$ \\
\hline \multicolumn{3}{|l|}{ Gender, $n$ (\%) } \\
\hline Male & $45,457(40)$ & $13,496,731(49)$ \\
\hline Female & $68,404(60)$ & $14,119,642(51)$ \\
\hline \multicolumn{3}{|l|}{ Health Plan, $n(\%)$} \\
\hline Comprehensive/Indemnity & $13,128(12)$ & $1,366,332(5)$ \\
\hline $\mathrm{EPO} / \mathrm{PPO}$ & $62,100(55)$ & $15,751,867(57)$ \\
\hline POS/POS w/capitation & $7,806(7)$ & $2,128,553(8)$ \\
\hline $\mathrm{HMO}$ & $16,430(14)$ & $4,235,960(15)$ \\
\hline $\mathrm{CDHP} / \mathrm{HDHP}$ & $6,905(6)$ & $2,109,739(8)$ \\
\hline Missing/Unknown & $7,492(7)$ & $2,023,922(7)$ \\
\hline \multicolumn{3}{|l|}{ Primary Insurance, n (\%) } \\
\hline Commercial & $89,495(79)$ & $25,416,170(92)$ \\
\hline Medicare & $24,366(21)$ & $2,200,203(8)$ \\
\hline \multicolumn{3}{|l|}{ Geographic Region, $n$ (\%) } \\
\hline Northeast & $20,268(18)$ & $5,113,594(19)$ \\
\hline North Central & $29,490(26)$ & $6,765,658(25)$ \\
\hline South & $40,575(36)$ & $9,976,789(36)$ \\
\hline West & $22,653(20)$ & $5,471,074(20)$ \\
\hline Unknown Region & $875(1)$ & $289,258(1)$ \\
\hline \multicolumn{3}{|l|}{ Employee classification, $n$ (\%) } \\
\hline Employee, salaried & $11,441(10)$ & $2,246,437(8)$ \\
\hline Employee, hourly & $14,944(13)$ & $2,524,118(9)$ \\
\hline Employee, unknown & $48,419(43)$ & $9,006,547(33)$ \\
\hline Spouse or dependent & $39,057(34)$ & $13,839,271(50)$ \\
\hline \multicolumn{3}{|l|}{ Employee Relationship, n (\%) } \\
\hline Employee & $74,804(66)$ & $13,777,102(50)$ \\
\hline Spouse & $30,900(27)$ & $5,415,157(20)$ \\
\hline Child/Other & $8,157(7)$ & $8,424,114(31)$ \\
\hline
\end{tabular}

$H M O$ health maintenance organization, $P O S$ point-of-service, $P P O / E P O$ preferred provider organization/exclusive provider organization, CDHP/HDHP consumer-driven health plan/high-deductible health plan

\section{Discussion}

The current study demonstrates that despite the availability of $\mathrm{HZ}$ vaccine, incidence of herpes zoster among an insured population has not decreased. A total of 
113,871 immunocompetent patients with HZ were analyzed in this retrospective study. The overall annual $\mathrm{HZ}$ incidence rate for the year 2011 was 4.47 per 1,000 person-years in our dataset and 4.63 per 1,000 personyears when standardized for age and sex using 2010 US Census data.

Understanding the age-specific incidence rate of $\mathrm{HZ}$ is important as they represent the target population for zoster vaccine. Consistent with other studies, the risk of HZ increased with advancing age. The age-specific incidence ranged from 0.86 per 1000 person-years in individuals $<19$ years of age to 12.78 per 1000 person-years among those 80 years of age and older, and increased rapidly after 50 years of age. The age-related increase in the incidence may be closely linked to an age-dependent decline in VZV-specific cell-mediated immunity. However, the U.S. Food and Drug Administration approval of the zoster vaccine for use in adults over 50 years of age contrasts recommendations from the ACIP which recommends vaccination of adults 60 years and older [11]. A substantial public health burden of $\mathrm{HZ}$ also occurs in adults 50 to 59 years of age, most of whom are working adults. In our study, over $25 \%$ of $\mathrm{HZ}$ occurred in adults 50 to 59 years of age and another $34 \%$ occurred in adults $>60$ years of age in the US.

Our age- and sex-standardized estimated rate of 4.6 cases per 1,000 person-years among immunocompetent patients is comparable to recent studies using administrative data in the US. Previously, reported rates were 4.8 per 1,000 person-years from the general population that includes immunocompromised individuals in 2005-09 [8] and 4.4 per 1,000 person-years in 2006 [9]. Similarly, Yawn and colleagues reported incidence rates of 3.6 per 1,000 person-years in a population-based study in Minnesota that incorporated medical record review from 1996 to 2001 [5]. Another study which utilized the MarketScan databases, reported an incidence rate of $\mathrm{HZ}$ of 3.2 per 1,000 person-years in years 2000-2001 [7]. Studies conducted more than 20 years ago in the US showed even lower rates: 2.2 in years 1990-1992 [18] and 1.3 per 1,000 person-years in years 1945-1959 [19]. This trend over time is consistent with most studies that examined temporal trends in the US and six other countries across the globe [2, 9, 20-23].

We observed a higher incidence rate of $\mathrm{HZ}$ in women than men (5.2 versus 3.7 per 1,000 person-years, respectively) across all age groups. Although some studies found no difference, the majority of prior studies from across countries also found that women have a greater risk of $\mathrm{HZ}$ than men [1, 5, 20-22, 24-27]. This difference may be partly due to differences in health seeking behavior; however, the difference may also be due to biological factors. In the Shingles Prevention Study clinical trial where participants were actively followed up and cases were laboratory-confirmed, women had higher incidence rates of $\mathrm{HZ}$ than men in the placebo group (11.79 versus 10.65 per 1,000 person-years, respectively) [6]. It is plausible that there may be immunological or hormonal differences between women and men in response to reactivation of latent virus infection.

As with all retrospective studies, the current investigation has potential limitations. First, the study was limited to only those individuals with commercial health coverage or private Medicare supplemental coverage in the US; therefore, results may not be generalizable to $\mathrm{HZ}$ patients with other insurance or without coverage or those living outside the US. Second, the potential for misclassification of $\mathrm{HZ}$, covariates, or study outcomes was potentially present as patients were identified through administrative claims data which are subject to data coding limitations and data entry error as opposed to medical records. However, previous studies found that the positive predictive value of ICD-9-CM codes for $\mathrm{HZ}$ in administrative claims data is relatively high, ranging from 84 to $94 \%[18,28,29]$. Third, since the zoster vaccine was approved in 2008 and this study only looked back 90 days prior to January 1, 2011 for evidence of vaccination, it is possible that both vaccinated and unvaccinated patients are included in the calculation. Fourth, this study used only one year of data to calculate incidence and may not represent the actual incidence if by any chance there were more or less cases reported in 2011. This study offers advantages, including the most updated estimate based on a nationwide administrative database in the US In addition, this study is based on a substantial number of datasets evaluated from two large administrative databases which allowed us to estimate the age- and sex-specific incidence rates in the immunocompetent population.

\section{Conclusions}

Despite the availability of a vaccine, herpes zoster remains common among immunocompetent adults with incidence rates of $\mathrm{HZ}$ observed to increase with age and be higher in women than men. A significant focus on how to reduce the risk of $\mathrm{HZ}$, e.g. improving vaccine access, should be adopted by health care providers.

\section{Additional file}

Additional file 1: Incidence of Herpes Zoster among Immunocompetent Adults by Age and Gender. This table contains the full set of incidence rates by age and by gender with confidence intervals. Please view this file as landscape. (DOC $45 \mathrm{~kb}$ )

\section{Competing interests}

BHJ, LP and GL are employees of Truven Health Analytics, which was awarded a research contract by Merck \& Co., Inc to conduct this study. JG was an employee of Truven Health Analytics at the time of the study and 
during manuscript preparation. KK was a consultant working for Merck \& Co., Inc at the time of the study and during manuscript preparation. CJA is an employee and stock holder of Merck \& Co., Inc.

\section{Authors' contributions}

$B H J, L P, K K$, and CJA were responsible for the concept and design of the study; BHJ, JG and KK were responsible for study coordination; GL performed the statistical analysis. All authors had full access to the study data and contributed substantially to the data analysis and interpretation of data, contributed to and critically reviewed the manuscript during its development, and approved the final version of the manuscript for submission.

\section{Acknowledgements}

The authors wish to acknowledge the analytic contributions of Helen Varker and Diana Stetsovsky and Santosh Tiwari for his editorial contribution to this study.

\section{Author details}

'Outcomes Research, Truven Health Analytics, Ann Arbor, MI, USA. ${ }^{2}$ Vaccines, Center for Observational and Real-World Evidence (CORE), Merck \& Co., Inc., West Point, PA, USA.

Received: 31 March 2015 Accepted: 3 November 2015

Published online: 06 November 2015

\section{References}

1. Thomas SL, Hall AJ. What does epidemiology tell us about risk factors for herpes zoster? Lancet Infect Dis. 2004;4(1):26-33.

2. Brisson M, Edmunds WJ, Law B, Gay NJ, Walld R, Brownell M, et al. Epidemiology of varicella zoster virus infection in Canada and the United Kingdom. Epidemiol Infect. 2001;127:305-14.

3. Schmader K. Herpes zoster in older adults. Clin Infect Dis. 2001;32:1481-6.

4. Kilgore PE, Kruszon-Moran D, Seward JF, Jumaan A, Van Loon FP, Forghani B, et al. Varicella in Americans from NHANES III: implications for control through routine immunization. J Med Virol. 2003;70 Suppl 1:S111-8.

5. Yawn BP, Saddier P, Wollan PC, St Sauver JL, Kurland MJ, Sy LS. A population-based study of the incidence and complication rates of herpes zoster before zoster vaccine introduction. Mayo Clin Proc. 2007;82:1341-9.

6. Oxman MN, Levin MJ, Johnson GR, Schmader KR, Straus SE, Gelb LD, et al. A vaccine to prevent herpes zoster and postherpetic neuralgia in older adults. N Engl J Med. 2005;352:2271-84.

7. Insinga RP, Itzler RF, Pellissier JM, Saddier P, Nikas AA. The incidence of herpes zoster in a United States Administrative Database. J Gen Intern Med. 2005;20:748-53.

8. Chen SY, Suaya JA, Li Q, Galindo CM, Misurski D, Burstin S, et al. Incidence of herpes zoster in patients with altered immune function. Infection. 2014:42(2):325-34.

9. Leung J, Harpaz R, Molinari NA, Jumaan A, Zhou F. Herpes zoster incidence among insured persons in the United States, 1993-2006: evaluation of impact of varicella vaccination. Clin Infect Dis. 2011;52(3):332-40.

10. Kawai K, Gebremeskel B, Acosta CJ. Incidence and complications of herpes zoster: towards a global perspective. BMJ Open. 2014;4(6):e004833.

11. Centers for Disease Control and Prevention. Prevention of Herpes Zoster. Recommendations of the Advisory Committee on Immunization Practices (ACIP). MMWR. 2008;57(Early Release):1-30.

12. Schmader KE, Levin MJ, Gnann Jr JW, McNeil SA, Vesikari T, Betts RF, et al. Efficacy, safety, and tolerability of herpes zoster vaccine in persons aged 50-59 years. Clin Infect Dis. 2012;54(7):922-8.

13. Kawai K, Preaud E, Baron-Papillon F, Largeron N, Acosta CJ. Costeffectiveness of vaccination against herpes zoster and postherpetic neuralgia: a critical review. Vaccine. 2014;32(15):1645-53.

14. Centers for Disease Control and Prevention. Noninfluenza vaccination coverage among adults — United States, 2011. MMWR. 2013;62:66-72.

15. United States' Census 2010. Available at: http://www.census.gov/ 2010census/. Last accessed on 6 Sep 2014

16. O'Malley CD, Johnston SS, Lenhart G, Cherkowski G, Palmer L, Morgan SL. Trends in dual-energy $X$-ray absorptiometry in the United States, 2000-2009. J Clin Densitom. 2011;14(2):100-7.

17. Chiang CL. Standard error of the age-adjusted death rate. US Department of Health, Education and Welfare. Vital Stat Spec Rep. 1961;47:271-85.
18. Donohue JG, Choo PW, Manson JE, Platt R. The incidence of herpes zoster. Arch Intern Med. 1995;155:1605-9.

19. Ragozzino MW, Melton 3rd LJ, Kurland LT, Chu CP, Perry HO. Populationbased study of herpes zoster and its sequelae. Medicine (Baltimore). 1982;61(5):310-6.

20. Hales CM, Harpaz R, Joesoef MR, Bialek SR. Examination of links between herpes zoster incidence and childhood varicella vaccination. Ann Intern Med. 2013;159(11):739-45.

21. Esteban-Vasallo MD, Gil-Prieto R, Domínguez-Berjón MF, Astray-Mochales J, Gil de Miguel A. Temporal trends in incidence rates of herpes zoster among patients treated in primary care centers in Madrid (Spain), 2005-2012. J Infect. 2014;68(4):378-86.

22. Toyama N, Shiraki K, Dermatologists SotMP. Epidemiology of herpes zoster and its relationship to varicella in Japan: A 10-year survey of 48,388 herpes zoster cases in Miyazaki prefecture. J Med Virol. 2009;81(12):2053-8.

23. Wu PY, Wu HD, Chou TC, Sung FC. Varicella vaccination alters the chronological trends of herpes zoster and varicella. PLoS One. 2013;8(10):e77709.

24. Chapman RS, Cross KR, Fleming DM. The incidence of shingles and its implications for vaccination policy. Vaccine. 2003;21:2541-47.

25. Morant-Talamante N, Diez-Domingo J, Martínez-Úbeda S, Puig-Barberá J, Alemán-Sánchez S, Pérez-Breva L. Herpes zoster surveillance using electronic databases in the Valencian Community (Spain). BMC Infect Dis. 2013;13:463.

26. Gonzalez Chiappe S, Sarazin M, Turbelin C, Lasserre A, Pelat C, Bonmarin I, et al. Herpes zoster: Burden of disease in France. Vaccine. 2010;28(50):7933-8.

27. Lin YH, Huang LM, Chang IS, Tsai FY, Lu CY, Shao PL, et al. Disease burden and epidemiology of herpes zoster in pre-vaccine Taiwan. Vaccine. 2010;28(5):1217-20.

28. Yawn BP, Wollan P, St. Sauver J. Comparing shingles incidence and complication rates from medical record review and administrative database estimates: How close are they? Am J Epidemiol. 2011;174(9):1054-61.

29. Klompas M, Kulldorff M, Vilk Y, Bialek SR, Harpaz R. Herpes zoster and postherpetic neuralgia surveillance using structured electronic data. Mayo Clin Proc. 2011;86(12):1146-53.

\section{Submit your next manuscript to BioMed Central and take full advantage of:}

- Convenient online submission

- Thorough peer review

- No space constraints or color figure charges

- Immediate publication on acceptance

- Inclusion in PubMed, CAS, Scopus and Google Scholar

- Research which is freely available for redistribution

Submit your manuscript at www.biomedcentral.com/submit
C) Biomed Central 